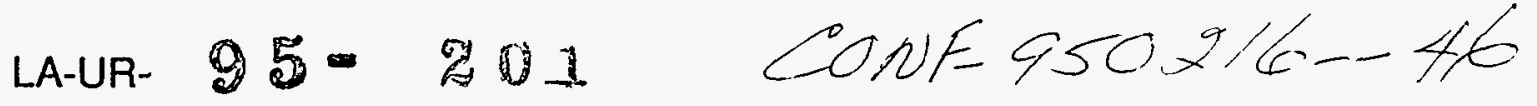

\title{
Title: MODELING PRECIPITATION FROM CONCENTRATED SOLUTIONS WITH THE EQ3/6 CHEMICAL SPECIATION CODES
}

$\begin{array}{ll}\text { Author(s): } & \begin{array}{l}\text { Lee F. Brown } \\ \text { Michael H. Ebinger }\end{array}\end{array}$

Submitted to:

Waste Management '95 Conference

Tucson, $A Z$

February 26 - March 2, 1995

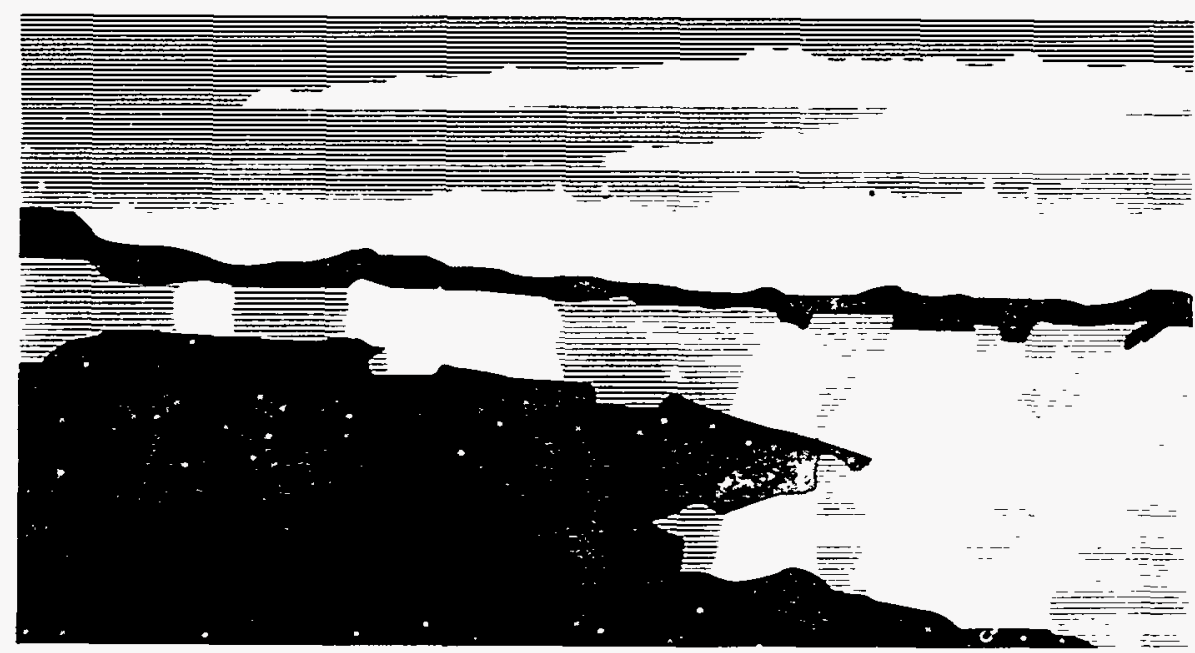

Los Alamos National Laboratory, an affirmative action/equal opportunity employer, is operated by the University of California for the U.S. Department of Energy under contract W.7405-ENG-36. By acceptance of this article, the publisher recognizes that the U.S. Government retains a nonexclusive, royalty-free license to publish or reproduce the published form of this contribution, or to allow others to do so, for U.S. Government purposes. The Los Alamos Natınal Laboratory requests that the publisher identify this anicle as work performed under the auspices of the U.S. Departmen! of Energy. 


\section{DISCLAIMER}

Portions of this document may be illegible in electronic image products. Images are produced from the best available original document. 


\title{
Modeling Precipitation from Concentrated Solutions with the EQ3/6 Chemical speciation Codes
}

\author{
Lee F. Brown and Michael H. Ebinger \\ Technology and Safety Assessment and Earth and Environmental Science Divisions \\ Los Alamos National Laboratory, Los Alamos, NM 87544
}

\section{DISCLAIMER}

This report was prepared as an account of work sponsored by an agency of the United States Government. Neither the United States Government nor any agency thereof, nor any of their employees, makes any warranty, express or implied, or assumes any legal liability or responsibility for the accuracy, completeness, or usefulness of any information, apparatus, product, or process disclosed, or represents that its use would not infringe privately owned rights. Reference herein to any specific commercial product, process, or service by trade name, trademark, manufacturer, or otherwise does not necessarily constitute or imply its endorsement, recommendation, or favoring by the United States Government or any agency thereof. The views and opinions of authors expressed herein do not necessarily state or reflect those of the United States Government or any agency thereof.

Paper for the

Waste Management '95 Conference

February 26 - March 2, 1995

Tucson, Arizona 


\section{INTRODUCTION}

One of the more important uncertainties of using chemical speciation codes to study dissolution and precipitation of compounds is the results of modeling depend on the particular thermodynamic database being used. Our goal is to investigate the effects of different thermodynamic databases on modeling precipitation from concentrated solutions. We used the EQ3/6 codes and the supplied databases to model precipitation in this paper. One aspect of our goal is to compare predictions of precipitation from ideal solutions to similar predictions from nonideal solutions. The largest thermodynamic databases available for use by EQ3/6 assume that solutions behave ideally. However, two databases exist that allow modeling nonideal solutions. The two databases are much less extensive than the ideal solution data, and we investigated the comparability of modeling ideal solutions and nonideal solutions.

We defined four fundamental problems to test the EQ3/6 codes in concentrated solutions. Two problems precipitate $\mathrm{Ca}(\mathrm{OH})_{2}$ from solutions concentrated in $\mathrm{Ca}^{*+}$. One problem tests the precipitation of $\mathrm{Ca}(\mathrm{OH})_{2}$ from high ionic strength (high concentration) solutions that are low in the concentrations of precipitating species $\left(\mathrm{Ca}^{++}\right.$in this case). The fourth problem evaporates the supernatant of the problem with low concentrations of precipitating species. The specific problems are discussed below.

The EQ3/6 chemical speciation codes satisfied simple qualitative consistency tests posed by the four elementary equilibrium problems. Precipitates showed higher solubilities when the solutions were regarded as nonideal than when they were considered ideal. The codes predicted almost complete precipitation when solids were of low solubility. Both of these qualitative aspects agree with expectations and chemical theory. The speciation codes also satisfied the simple quantitative consistency tests posed by the same four problems. Solubility products were identical when they were derived from the same database, and numerically close when they were calculated with values from different databases. Mass balances in each problem were consistent regardless of the approach used on a particular problem. The calculations converged to values of concentration and activity coefficients which gave solubility products close to those listed in the databases and those calculated from listed Gibbs free energy data.

The results from solving the four problems using different databases suggests that the amounts of precipitates predicted from ideal solutions were similar to those predicted from nonideal solutions when the initial concentration of the precipitating species is high. The similarity in results between the ideal and nonideal approaches decreases when the initial concentration of the precipitating species is low. There is significant discrepancy in the activity coefficients calculated as expected. The largely nonideal activity coefficients, however, tend to cancel when the $\mathrm{K}_{\mathrm{sp}}$ values are calculated from the speciation data and provide apparent agreement between the nonideal and ideal predictions of solubility.

The results of the simulations presented in this paper show clearly the need to use carefully speciation codes as tools for predicting chemical behavior of solutions. Uncertainty in calculating activity coefficients, redox states, and ionic interactions in general leads to variation in the results of modeling precipitation and dissolution (Nordstrom, 1979). Users of speciation codes must also be aware of the data used in the calculations of different values and the limitations of the databases used for the calculations. Daveler and Wolery (1992) discuss specifically the limitations of the EQ3/6 databases.

\section{METHODS}

\section{Overview of Problems}

We designed four problems to test the EQ3/6 codes in modeling precipitation of $\mathrm{Ca}(\mathrm{OH})_{2}$ (portlandite) and $\mathrm{CaSO}_{4}$ (gypsum) in concentrated solutions. Problem \#1 concerned the precipitation of a single substance, $\mathrm{Ca}(\mathrm{OH})_{2}$ (portlandite). One liter of a water solution containing $500 \mathrm{~g}$ dissolved $\mathrm{CaCl}_{2}$ was mixed at $25^{\circ} \mathrm{C}$ with one liter of a water solution containing $100 \mathrm{~g}$ dissolved $\mathrm{NaOH}$. We determined how much portlandite precipitated and the composition of the remaining solution. 
Problem \#1 served to validate the EQ3/6 codes on an elementary level. In this problem, the solutions are concentrated and calcium is in excess, so most of the hydroxyl ion will precipitate as $\mathrm{Ca}(\mathrm{OH})_{2}$. A second purpose is to examine the variation in activity coefficients and ion activities that result from using the different equations and databases embedded in the EQ3/6 codes.

Problem \#2 studies precipitation from a concentrated solution but dilute in precipitating species. One-liter batches of three solutions were mixed together at $25^{\circ} \mathrm{C}$. One liter of a solution containing $8 \mathrm{~g}$ dissolved $\mathrm{CaCl}_{2}$, one liter of a water solution containing $3 \mathrm{~g}$ dissolved $\mathrm{NaOH}$, and one liter of a water solution containing $500 \mathrm{~g}$ dissolved $\mathrm{NaCl}$ are mixed. We determined if calcium hydroxide precipitated, and if so, how much. We also determined the concentration of the remaining solution.

Problem \#3 investigated simultaneous precipitation of portlandite and $\mathrm{CaSO}_{4} \cdot 2 \mathrm{H}_{2} \mathrm{O}$ (gypsum). The purpose of Problem \#3 was to compare relative amounts of two precipitates, both of which should form because of the concentrated solution. One-liter batches of three solutions were mixed at $25^{\circ} \mathrm{C}$. One liter of a solution containing $500 \mathrm{~g}$ dissolved $\mathrm{CaCl}_{2}$, one liter of a solution containing $100 \mathrm{~g}$ dissolved $\mathrm{NaOH}$, and one liter of a solution containing $500 \mathrm{~g}$ dissolved $\mathrm{Na}_{2} \mathrm{SO}_{4}$ were mixed. We determined how much calcium hydroxide and how much gypsum precipitated and the composition of the remaining the solution.

The fourth problem examines the evaporation of the supernatant of Problem \#3. We determined the precipitates after evaporation of most of the supernatant. The supernatant was evaporated from $100 \mathrm{~g}$ of $\mathrm{H}_{2} \mathrm{O}$ to $45 \mathrm{~g}$. Problem \#4 illustrates possible differences in the predicted results of evaporation campaigns when different thermodynamic databases are used to calculate the solution compositions.

The problems above problems were designed to test several hypotheses: 1) ideal and nonideal calculations provide similar predictions of the precipitation processes; 2 ) activity coefficients vary in calculations using different strategies for calculating them; 3 ) solubility constants calculated from the solutions speciated by the EQ3/6 codes agree with solubility constants calculated from the corresponding databases.

\section{Calculation of Activity Coefficients}

The "tendency of a species to react" (Campbell 1970) is the activity of a substance. Activities are used to calculate thermodynamic equilibrium constants and solubility products $\left(K_{s p}\right)$. The solubility products predict precipitation of solids from solutions and dissolution of solids into solutions. Thermodynamic activity $\left(a_{i}\right)$ of a component is calculated from its concentration $\left(C_{i}\right)$ and activity coefficient $\left(\gamma_{i}\right)$ by

$$
a_{i}=\gamma_{i} C_{i}
$$

Activity coefficients approach one in highly dilute solutions and are defined as unity in ideal solutions.

The first successful approacr, to estimating activity coefficients for species in ionic solutions was proposed by Debye and Hückel (1923). Their approach has been widely used and extended since its introduction. Glasstone (1946) and Lewis and Randall (1961) give good descriptions of the theory and its applications, and Mazo and Mou (1979) give a sophisticated treatment of Debye - Hückel theory.

Unmodified Debye-Hückel theory may be suitable for modeling solutions only at concentrations less than $0.003 \mathrm{M}$ (Frank and Thompson, 1959). Thus, unmodified Debye-Hückel equations are not used in the EQ3/6 codes. An extended Debye-Hückel equation proposed by Davies (1962) is incorporated in EQ3/6 as is the "B-dot" equation (Helgeson, 1969; Johnson and Pytkowicz, 1979). Activity coefficients calculated from high concentration solutions, however, are in error even when these modifications to Debye-Hückel theory are employed. Recent modeling efforts have incorporated virial equations developed by Pitzer for activity coefficients (e.g., Pitzer 1979, 1991; Clegg and Whitfield 1991). Use of virial equations allow more exact calculation of activity coefficients for solutions at high concentrations. 


\section{Chemical Speciaition: EQ3/6 Codes}

Several chemical speciation codes have been developed since about 1965 . The characteristics of some of the codes are compared by Mangold and Tsang (1991). We use the EQ3/6 codes codes (Wolery 1979, $1992 a, 1992 b$ ) because of the ability to model more aqueous species and more possible precipitated mineral types than the other codes. The EQ3/6 codes also model the evolution of a solution from its starting point toward final equilibrium. The final solution and any intermediate solutions and precipitates can be examined during the course of reaction path modeling. Few other chemical speciation codes have this capability.

The EQ3/6 codes have undergone continuous improvement. Since the Mangold-Tsang table was developed, the capabilities of EQ3/6 have been expanded further. The number of elements included in the most frequently used database has increased from 47 to 78 , the number of aqueous species from 686 to 851 , of minerals from 713 to 885 , and of gases from 11 to 75 (Daveler and Wolery 1992).

According to Wolery (1992a), the COM file is the largest of the five databases and draws on many sources of data. It encompasses the broadest range of elements and species of any of the five files, taking some of its data from the other four files. The SUP file has a high level of internal consistency and was developed from the SUPCRT database (Johnson et al, 1992). The NEA file has a thorough representation of the thermodynamics of uranium species.

The Pitzer equations require specific parameters, and databases developed particularly for using these equations are necessary. The PIT and the HMW data files were created for using the EQ3/6 codes with the Pitzer equations. The PIT file includes more species, but the HMW file has better internal consistency. The HMW file includes mutual consistency of activity coefficient data and standard state thermodynamic data. However, the HMW file is limited to the set of components present in the "sea-salt" system, and is restricted to $25^{\circ} \mathrm{C}$. Wolery $(1992 \mathrm{~b})$ and Daveler and Wolery (1992) give additional information about these database files.

\section{The Databases and Activity-Coefficient Relationships Used in this Study.}

Employing the Pitzer equations for the concentrated solutions in Problems \#1-4 was the first choice of prediction methods. The number of solution species and solids available in the PIT database, however, is not as extensive as the databases for the Debye-Hückel approach. Therefore, while the Pitzer approach is preferable from a theory standpoint, the data necessary for adequate description of the problems dictates the use of the Debye-Hückel approach. Because of the inaccuracy of the Debye-Hückel approach in modeling activity coefficients at high concentrations, an indication of the errors involved in using the Debye-Hückel approach is desirable.

The Davies and B-dot equations were used with the COM database to compare the results of the two approaches and a single database. The Pitzer equations were used with the PIT and HMW databases to compare this approach with different databases. The results of each problem allowed comparison of the Debye-Hückel and Pitzer equations in examining the four problems.

\section{RESULTS AND DISCUSSION}

\section{Precipitation Problem \#1}

The amount of portlandite that precipitated in the different solutions to Problem \#1 ranged from $44.9 \mathrm{~g} / \mathrm{M}$ to $46.3 \mathrm{~g} / \mathrm{M}$ (Table I). The higher value was calculated using ideal solution computations, the lower value with EQ3/6 and adjusted for nonideality. The ideal solution computation was expected to be greater than the nonideal computation because nonideal activity coefficients tend to be less than one resulting in higher solubility (less precipitation). The low $\mathrm{K}_{\mathrm{sp}}$ for portlandite ensured that most of the $\mathrm{Ca}^{\text {t+ }}$ precipitated and there was little $\mathrm{Ca}^{++}$in solution and minimal effect of nonideal activity coefficients in the calculations. The 
low $\mathrm{K}_{\mathrm{sp}}$ gives reasonable predictions of the amounts of $\mathrm{Ca}(\mathrm{OH})_{2}$ precipitation for Problem \#1 regardless of ideality or nonideality of the activity coefficients.

The activity coefficients for both the $\mathrm{Ca}^{++}$and $\mathrm{OH}^{-}$ions show wide variation. The coefficients for the calcium ion range from 0.35 to 2.65 and for the hydroxyl ion from 0.035 to 0.57 . There seems to be little consistency in the activity coefficients, either within the same database using different relationships for the coefficients, or within the same relationship but using different databases. The listed concentrations are dilute, so they do not differ much in absolute terms. They nevertheless exhibit significant relative differences. The existence of these differences illustrates the uncertainties in using computer codes for chemical speciation as mentioned above.

\section{Precipitation Problem \#2}

Table Il shows the results of Precipitation Problem \#2. Ideal solutions show small amounts of portlandite precipitating, whereas three of the four nonideal calculations show no portlandite precipitation. Since the solubilities are generally higher for solids in nonideal solutions, there șhould be a possibility that no precipitation is predicted when nonideal solutions are modeled. The Pitzer calculations using the HMW database predicted no precipitation even though a precipitate was predicted when the PIT database was used. The reason for the discrepancy is that the $\mathrm{K}_{\mathrm{sp}}$ value for $\mathrm{Ca}(\mathrm{OH})_{2}$ in the $\mathrm{HMW}$ database was significantly lower than in the PIT database.

Precipitates were considered more likely in the simulations using the Pitzer equations than in the DebyeHückel simulations. The Debye-Hückel relationships tend to predict activity coefficients that are lower than the coefficients from the Pitzer equations when solutions are concentrated. The expected outcome is reflected in Table II when the low value of the $\mathrm{K}_{\mathrm{sp}}$ in the HMW database is factored into the comparison.

The difference in the precipitated masses predicted by the two ideal-solution calculations shows the significance of a small variation in solubility products. There is a $12 \%$ difference in the masses of the precipitates from the two predictions, resulting from a variation of about $16 \%$ in the listed solubility products. A larger difference in the listed solubility products, such those of $\mathrm{CaSO}_{4}$ (Table III) could be significant in predicting precipitation or no precipitation from different solutions.

\section{Precipitation Problem $\$ 3$}

Gypsum and portlandite were precipitated simultaneously in Problem \#3. The amounts of portlandite precipitated ranged from $28.6-29.8 \mathrm{~g} / \mathrm{M}$, and the amounts of gypsum were grouped in the range 181.3 to $192.0 \mathrm{~g} / \mathrm{M}$ (Table III). The exception was $26.3 \mathrm{~g} / \mathrm{M} \mathrm{Ca}(\mathrm{OH})_{2}$ and $197.6 \mathrm{~g} / \mathrm{M} \mathrm{CaSO}_{4} \cdot 2 \mathrm{H}_{2} \mathrm{O}$ that resulted from the unusually low $\mathrm{K}_{\mathrm{sp}}$ for gypsum in one of the data sources used for evaluating ideal solutions.

The nonideal and ideal solution predictions produced similar amounts of portlandite and gypsum. The consistency in the precipitates is illustrater by the following. Let $x$ be the amount of $\mathrm{Ca}^{++}$ion that precipitated as $\mathrm{Ca}(\mathrm{OH})_{2}$ and $y$ the amount of $\mathrm{Ca}^{++}$ion that precipitated as $\mathrm{CaSO}_{4} \cdot 2 \mathrm{H}_{2} \mathrm{O}$. The ratio $y / x$ ranged from 2.66 to 2.77 for the nonideal calculations and was 2.89 for the ideal calculation. The ratios of $x_{\text {real }} / x_{\text {ideal }}$ ranged only from 1.01 to 1.02 . In the case of Problem \#3, use of the ideal-solution results would have predicted realistic amounts of portlandite and gypsum precipitating. The nonideality of the solution did not change the amounts of each species precipitating very much.

The results of Problem \#3 show the effects of higher solubility in nonideal solutions. In each case the calculated gypsum precipitate was less when nonideality was considered than when the solutions were assumed ideal. As in Problem \#1 there is a wide range of ion concentrations and activities with little consistency observable.

Precipitation Problem \#4 
Problem \#4 begins with the final solution of Problem \#3. The concentrations of various ions in each case of Problem \#3 varied, so the starting concentrations of each prediction for Problem \#4 were not equal. Thus, it was expected that the amounts of precipitates predicted from different approaches would not be very similar (Table IV). Water wàs evaporated to $45 \mathrm{~g}$ from $1000 \mathrm{~g}$ in each calculation. Each nonideal calculation predicted that four minerals would precipitate-portlandite, halite $(\mathrm{NaCl})$, thenardite $\left(\mathrm{Na}_{2} \mathrm{SO}_{4}\right)$, and glauberite $\left(\mathrm{Na}_{2} \mathrm{Ca}\left(\mathrm{SO}_{4}\right)_{2}\right)$. No other minerals were predicted to precipitate by any of the calculations.

Halite is the main component of the precipitate comprising $91-94 \%$ of the mass of the precipitate. Halite precipitates because the starting solutions contained large amounts of soluble sodium and chloride ions from the original solution for Problem \#3. Calcium, hydroxyl, and sulfate ions had largely been removed in the precipitates predicted in Problem \#3. The two calculations using the Pitzer activity-coefficient relationships predicted about $10 \%$ more halite precipitating than the two calculations using Debye-Hückel activity-coefficient relationships.

The reason for the Pitzer calculations predicting more halite precipitating than the Debye-Hückel calculations is not clear. In spite of the different relationships and different databases, the ionic concentrations in the water are not greatly different, nor are the calculated activity coefficients. The principal difference in the calculations seems to be the larger number of aqueous species considered in the Debye-Hückel calculations, and the concentrations of these species remaining in solution. This result illustrates the importance of knowing the contents of the databases used for predictions.

The predicted amounts of portlandite, thenardite, and glauberite differed significantly among the calculations. The high value of portlandite is $46 \%$ above the low value, the high value of thenardite is $44 \%$ above the low value, the high value of glauberite is over twice the low value. There seems to be little correlation of the high and low values with the methods of calculation. The cause for the range of values in the results could lie in the number and kind of species considered, the databases utilized, or the equations used to calculate the activity coefficients.

There is also a large variation in the ion concentrations and activity coefficients. Variations in the results of the Pitzer activity-coefficient relationships are less than the variations in the results derived from the Debye-Hackel relationships. The Pitzer relationships are supposed to be more appropriate for concentrated solutions, and they show that quality here.

\section{Mass Balances}

(The next 3 paragraphs are just taken from the earlier results writeups. Significant additions and revisions need to be made in light of the complete Table 7.)

Concerning Precipitation Problem \#1, for the two COM database calculations, the table does not contain all the calcium species that the code considered, so the table's listing cannot be used for mass balance on calcium. The species $\mathrm{CaCl}_{2}(\mathrm{aq}), \mathrm{CaCl}^{+}$, and $\mathrm{CaOH}^{+}$are not listed in the table. When they are taken into account, the mass balances on calcium for all four situations check to within 2 in the fourth significant figure (Table 7).

Concerning Precipitation Problem \#3, for some of the calculations, the table does not contain all the calcium or sulfur species that the code considered, so the table's listings cannot be used for a mass balance on these materials. The species $\mathrm{NaSO}^{-}, \mathrm{CaCl}_{2}(\mathrm{aq}), \mathrm{CaSO}_{4}(\mathrm{aq}), \mathrm{CaCl}^{+}$, and $\mathrm{CaOH}^{+}$are not listed in the table. The concentrations of all these are small when considered in the calculations, but their aggregate does affect the mass balance. The calcium and sulfur mass balances for all four situations check well---to 2 in the fourth significant figure for calcium, to 5 in the fourth significant figure for sulfur (Table 7).

Concerning Precipitation Problem \#4, it is mentioned above that the Debye-Hückel-based calculations include more species than the Pitzer-based calculations. For some of the calculations, the table does not 
contain all the sodium, calcium, chlorine, or sulfur species that the code considered, so the table's listings cannot be used for a mass balance on these materials. The aqueous species $\mathrm{NaCl}(\mathrm{aq}), \mathrm{NaOH}(\mathrm{aq})$, $\mathrm{NaSO}_{4}{ }^{-}, \mathrm{CaCl}_{2}(\mathrm{aq}), \mathrm{CaSO}_{4}(\mathrm{aq}), \mathrm{CaCl}^{+}$, and $\mathrm{CaOH}^{+}$are not listed in the table. The concentrations of all these are small when considered in the calculations, but their aggregate does affect the mass balance. (The mass balances for this problem still have to be checked.)

\section{(to be continued)}

\section{Solubility Products}

We discussed above that variation of solubility products from different models can be significant and occasionally drastic. For example, the solubility product of gypsum from the two sources used for idealsolution calculations in Problem \#3 differ by a factor of 7.8 and the portlandite solubility products from the same sources also differ significantly (17\%). One test of the consistency of different thermodynamic databases was to calculate solubility products from the concentration and activity coefficient information, then compare the calculated $K_{\mathrm{sp}}$ to the database values. The EQ3/6 calculations show excellent agreement between calculated and reference (database) solubility products of the different precipitates. The $K_{s p}$ values calculated for portlandite from the COM database agree well with the $K_{s p}$ in the database in Problems \#1 -\#3, and the same is true for gypsum in Problem \#3. The $K_{s p}$ calculated from the PIT and HMW databases agree with their respective reference $K_{s p}$ values. The PIT $K_{s p}$ values are essentially equivalent to the $K_{s p}$ values calculated from the COM database. The HMW KsD values are $78 \%$ greater than the PIT values for portlandite and $26 \%$ greater for gypsum. Although large, the differences in $\mathrm{K}_{\mathrm{sp}}$ between the PIT and HMW databases is within a factor of 2 which is a relatively small difference for $\mathrm{K}_{\mathrm{sp}}$ values.

The free energies of formation for the above constituents were identical in the COM and PIT databases. It is not surprising that the solubility products calculated using these databases are also identical. However, the solubility products calculated in Tables IIV are slightly different than the solubility products listed in the databases. The solubility products listed in the databases agree with solubility products hand calculated from free energy data in the databases. The differences between the solubility products calculated from the concentrations and activity coefficients and the ones listed in the databases are less than 0.11 in the Log $K_{\mathrm{sp}}$ values, but it is surprising that the differences exist. The difference is caused partly by convergence criteria used in the calculations.

\section{CONCLUSIONS}

Results of Problems \#1 and \#3 show that predicted precipitation from ideal agrees with predictions from non-ideal dolutions. The reason for the apparent agreement lies in the calculation of the $K_{s p}$ values. Activity coefficients calculated using non-ideal adjustments probably cancel when the $K_{s p}$ is calculated, thus the value of $\mathrm{K}_{\mathrm{sp}}$ is the ratio of the concentrations, and the difference between ideal and non-ideal approximations is minimal.

Results of Problem \#2 show that there is a significant difference in ideal and non-ideal predictions when the precipitating species are in low concentration and the solution is of high ionic strength (high concentration). Debye-Hückel relationships tend to predict lower activity coefficients in concentrated solutions than do Pitzer relationships. Results from B-dot calculations reflect the tendency to predict lower activity coefficients, but the Davies results show larger activity coefficients than calculated with the Pitzer equations. The reason for larger activity coefficients from the Davies equation is not clear. Results of Problem \#2 show the importance of including non-ideality in calculating precipitation from solutions dilute in the precipitating species.

The results of Problem \#2 also show the effects of different $K_{s p}$ values in different databases. The PIT and HMW databases show different values for the $K_{s p}$ of portlandite. The result is that calculations using the PIT database predicted precipitation of portlandite and those using the HMW database did not. 
Problem \#4 results show agreement in precipitation of Na-containing compounds when the ideal and nonideal calculations are compared. The starting solution is the supernatant of Problem \#3 and is concentrated with regard to $\mathrm{Na}^{+}$and $\mathrm{Cl}$, and agreement between the ideal and non-ideal predictions is expected in the $\mathrm{Na}$-containing precipitates. The results show that $\mathrm{Ca}$-containing solids do not agree when the ideal and non-ideal predictions are compared. The discrepancy in the Ca-containing compounds is due to low concentration of $\mathrm{Ca}^{++}$in the starting solution for Problem \#3. Non-ideality is important when the precipitating species are in low concentration. In Problem $\# 3 \mathrm{Ca}^{++}$precipitated from the ideal solution and the Pitzer calculation, but not in the other solutions. In Problem \#4 the Pitzer and ideal predictions precipitated the lowest masses of Ca-containing solids because there was less $\mathrm{Ca}^{++}$available to precipitate. There is still significant difference between the ideal and the four non-ideal predictions due to the effects of non-ideality on solubility of Ca-containing solids.

\section{REFERENCES}

Campbell, J. A., Chemical Systems: Energetic, Dynamics, Structure, pp. 722, 724. W. H. Freeman, San Francisco, CA, 1970.

Clegg, S. L., and M. Whitfield, "Activity Coefficients in Natural Waters," in Activity Coefficients in Electrolyte Solutions, 2nd ed. (K. S. Pitzer, ed.), pp. 279-434. CRC Press, Boca Raton, FL (1991).

Daveler, S. A., and T. J. Wolery, "EQPT, a Data File Preprocessor for the EQ3/6 Software Package: User's Guide and Related Documentation (Version 7.0)," Report UCRL-MA-110662 PT II, Lawrence Livermore National Laboratory, Livermore, CA (December 17, 1992).

Davies, C. W. Ion Association. Butterworths, London, 1962.

Debye, P., and E. Hückel, "Zur Theorie der Electrolyte," I and II, Phys. Z., 24, 185-206 and 305-325 (1923).

Dean, J. A., Lange's Handbook of Chemistry, 14th ed., pp. 8-6 to 8-11. McGraw-Hill, New York, 1992.

Frank, H. S., and P. T. Thompson, "Fluctuations and the Limit of Validity of the Debye-Hückel Theory," J. Chem. Phys., 31, 1086-1095 (1959).

Glasstone, S., Textbook of Physical Chemistry, pp. 956-974. Van Nostrand, New York, 1946.

Harvie, C. E., N. Møller, and J. H. Weare, "The Prediction of Mineral Solubilities in Natural Waters: the Na$\mathrm{K}-\mathrm{Mg}-\mathrm{Ca}-\mathrm{H}-\mathrm{Cl}-\mathrm{SO}_{4}-\mathrm{OH}-\mathrm{HCO}_{3}-\mathrm{CO}_{3}-\mathrm{CO}_{2}-\mathrm{H}_{2} \mathrm{O}$ System to High lonic Strengths at $25^{\circ} \mathrm{C}$, Geochimica et Cosmochimica Acta, 48, 723-751 (1984).

Helgeson, H. C., "Thermodynamics of Complex Dissociation in Aqueous Solutions at Elevated Temperatures," Am. J. Sci., 267, 729-804 (1969).

Johnson, J. W., E. H. Oelkers, and H. C. Helgeson, "SUPCRT92: A Software Package for Calculating the Standard Molal Thermodynamic Properties of Minerals, Gases, Aqueous Species, and Reactions from 1 to 5000 bars and $0^{\circ}$ to $1000^{\circ} \mathrm{C}$," Computers and Geosciences, 18, 899-947 (1992).

Johnson, K. S., and R. M. Pytkowicz, "Ion Association and Activity Coefficients in Multicomponent Solutions," in Activity Coefficients in Electrolyte Solutions, Vol. II (R. M. Pytkowicz, ed.), pp. 1-62, esp. p. 4. CRC Press, Boca Raton, FL (1979).

Lewis, G. N., and M. Randall, Thermodynamics; revised by K. S. Pitzer and L. Brewer, chap. 22. McGraw-Hill, New York, 1961. 
Lide, D. R. (ed.-in-chief), Handbook of Chemistry and Physics, 74th ed., p. 8-49. CRC Press, Boca Raton, FL, 1993.

Mangold, D. C., and C.-F. Tsang, "A Summary of Subsurface Hydrological and Hydrochemical Models," Rev. Geophysics, 29, 51-79 (1991).

Mazo, R. M., and C. Y. Mou, "Introduction to the Statistical Mechanics of Solutions," in Activity Coefficients in Electrolyte Solutions, Vol I (R. M. Pytkowicz, ed.), pp. 30-64, esp. 51-54. CRC Press, Boca Raton, FL (1979).

Nordstrom, D. K., L. N. Plummer, T. M. L. Wigley, T. J. Wolery, J. W. Ball, E. A. Jenne, R. L. Bassett, D. A. Crerar, T. M. Florence, B. Fritz, M. Hoffman, G. R. Holdren, Jr., G. M. Lafon, S. V. Mattigod, R. E. McDuff, F. Morel, M. M. Reddy, G. Sposito, and J. Thrailkill, "A Comparison of Computerized Chemical Models for Equilibrium Calculations in Aqueous Systems," in Chemical Modeling in Aqueous Systems (E. A. Jenne, ed.), ACS Symposium Series \# 93, pp. 857-892. American Chemical Society, Washington, DC, 1979.

Pitzer, K. S., "Theory: Ion Interaction Approach," in Activity Coefficients in Electrolyte Solutions, Vol I (R. M. Pytkowicz, ed.), pp. 157-208. CRC Press, Boca Raton, FL (1979).

Pitzer, K. S., "Ion Interaction Approach: Theory and Data Correlation," in Activity Coefficients in Electrolyte Solutions, 2nd ed. (K. S. Pitzer, ed.), pp. 75-153. CRC Press, Boca Raton, FL (1991).

Wolery, T. J., "Calculation of Chemical Equilibrium between Aqueous Solution and Minerals: The EQ3/6 Software Package," Report UCRL-52658, Lawrence Livermore National Lab., Livermore, CA, 1979.

Wolery, T. J., "EQ3/6, a Software Package for Geochemical Modeling of Aqueous Systems: Package Overview and Installation Guide (Version 7.0)," Report UCRL-MA-110662 PT I, Lawrence Livermore National Lab., Livermore, CA (September 14, 1992a).

Wolery, T. J., "EQ3NR, a Computer Program for Geochemical Aqueous Speciation-Solubility Calculations: Theoretical Manual, User's Gụide, and Related Documentation (Version 7.0)," Report UCRL-MA-110662 PT III, Lawrence Livermore National Lab., Livermore, CA (September 14, 1992b). 
Table I. Amounts of precipitate and solution properties from Problem \#1.

\begin{tabular}{|c|c|c|c|c|c|c|}
\hline & Ideal Solution $\# 1^{1}$ & Ideal Solution $\# 2^{2}$ & COM, Davies & COM, B-dot & PIT & HMW \\
\hline \multicolumn{7}{|c|}{ Precipitate Name and Amount (g/) } \\
\hline $\mathrm{Ca}(\mathrm{OH})_{2}$ & 46.3 & 46.3 & 45.4 & 45.4 & 45.9 & 44.9 \\
\hline \multicolumn{7}{|c|}{ Solution Properties (unitless unless noted) } \\
\hline $\mathrm{pH}$ & 11.2 & 11.3 & 11.4 & 11.7 & 11.8 & 11.9 \\
\hline$\left[\mathrm{Ca}^{++}\right], \mathrm{M}$ & 1.63 & 1.63 & 0.62 & 1.15 & 1.63 & 1.65 \\
\hline$\left[\mathrm{OH}^{\dagger}\right], \mathrm{M}$ & 0.002 & 0.002 & 0.003 & 0.006 & 0.012 & 0.038 \\
\hline${ }^{\gamma} \mathrm{Ca}^{++}$ & 1.00 & 1.00 & 2.65 & 0.35 & 2.26 & 2.21 \\
\hline${ }^{\gamma_{\mathrm{OH}^{-}}}$ & 1.00 & 1.00 & 0.57 & 0.55 & 0.084 & 0.035 \\
\hline $\mathrm{pK}_{\mathrm{sp}}^{3}$ (calc.) & & & 5.44 & 5.44 & 5.44 & 5.19 \\
\hline $\mathrm{pK}_{\mathrm{sp}}{ }^{4}$ (ref.) & 5.33 & $5.26^{2}$ & 5.21 & 5.21 & 5.21 & 5.19 \\
\hline
\end{tabular}

1 Solubility constant data from Lide (1993).

2 Solubility constant data from Dean (1992).

${ }^{3} \mathrm{~K}_{\mathrm{sp}}$ calculated from concentration and activity coefficient results.

${ }^{4} \mathrm{~K}_{\mathrm{sp}}$ calculated from standard free energy of formation in references or database. 
Table II. Amounts of precipitate and solution properties from Problem \#2.

\begin{tabular}{|c|c|c|c|c|c|c|}
\hline & $\begin{array}{c}\text { Ideal Solution } \\
\# 1^{1}\end{array}$ & $\begin{array}{c}\text { Ideal Solution } \\
\# 2^{2}\end{array}$ & COM, Davies & COM, B-dot & PIT & HMW \\
\hline \multicolumn{7}{|c|}{ Precipitate Name and Amount (gn) } \\
\hline $\mathrm{Ca}(\mathrm{OH})_{2}$ & 0.35 & 0.31 & 0.0 & 0.0 & 0.35 & 0.0 \\
\hline \multicolumn{7}{|c|}{ Solution Properties (unitless unless noted) } \\
\hline $\mathrm{pH}$ & 12.1 & 12.2 & 12.3 & 12.2 & 12.6 & 12.6 \\
\hline$\left[\mathrm{Ca}^{++}\right], \mathrm{M}$ & 0.019 & 0.020 & 0.013 & 0.019 & 0.019 & 0.024 \\
\hline$\left[\mathrm{OH}^{-}\right], \mathrm{M}$ & 0.016 & 0.017 & 0.023 & 0.028 & 0.040 & 0.049 \\
\hline$\gamma_{\mathrm{Ca}^{++}}^{+}$ & 1.00 & 1.00 & 1.08 & 0.23 & 0.59 & 0.49 \\
\hline$\gamma_{\mathrm{OH}^{-}}$ & 1.00 & 1.00 & 0.58 & 0.28 & 0.45 & 0.42 \\
\hline $\mathrm{pK}_{\mathrm{sp}}{ }^{4}$ (calc.) & & & n.d. ${ }^{3}$ & n.d. ${ }^{3}$ & 5.44 & n.d. $^{3}$ \\
\hline $\mathrm{pK}_{\mathrm{sp}}{ }^{5}$ (ref.) & 5.33 & 5.26 & 5.21 & 5.21 & 5.21 & 5.19 \\
\hline
\end{tabular}

1 Solubility constant data from Lide (1993).

2 Solubility constant data from Dean (1992).

${ }^{3}$ Solubility products not calculated because no precipitate formed.

${ }^{4} \mathrm{~K}_{\mathrm{sp}}$ calculated from concentration and activity coefficient results.

${ }^{5} K_{s p}$ calculated from standard free energy of formation in references or database. 
Table III. Amounts of precipitate and solution properties from Problem \#3.

\begin{tabular}{|c|c|c|c|c|c|c|}
\hline & $\begin{array}{c}\text { Ideal Solution } \\
\# 1^{1}\end{array}$ & $\begin{array}{c}\text { Ideal Solution } \\
\# 2^{2}\end{array}$ & COM, Davies & COM, B-dot & PIT & HMW \\
\hline \multicolumn{7}{|c|}{ Precipitate Name and Amount $(g /)$} \\
\hline $\mathrm{Ca}(\mathrm{OH})_{2}$ & 28.6 & 26.3 & 28.9 & 28.8 & 29.8 & 29.3 \\
\hline $\mathrm{CaSO}_{4} \cdot 2 \mathrm{H}_{2} \mathrm{O}$ & 192.0 & 197.6 & 185.9 & 181.3 & 184.1 & 184.7 \\
\hline \multicolumn{7}{|c|}{ Solution Properties (unitless unless noted) } \\
\hline $\mathrm{pH}$ & 12.8 & 13.1 & 12.2 & 12.3 & 12.2 & 12.3 \\
\hline$\left[\mathrm{Ca}^{++}\right], \mathrm{M}$ & 0.0012 & 0.0004 & 0.014 & 0.044 & 0.031 & 0.035 \\
\hline$\left[\mathrm{OH}^{-}\right], \mathrm{M}$ & 0.061 & 0.124 & 0.024 & 0.032 & 0.031 & 0.046 \\
\hline$\left[\mathrm{SO}_{4}^{-}\right], \mathrm{M}$ & 0.058 & 0.026 & 0.009 & 0.040 & 0.108 & 0.104 \\
\hline$\gamma_{\mathrm{Ca}^{++}}$ & 1.00 & 1.00 & 1.37 & 0.25 & 0.63 & 0.54 \\
\hline$\gamma_{\mathrm{OH}^{-}}$ & 1.00 & 1.00 & 0.58 & 0.57 & 0.44 & 0.40 \\
\hline $\mathrm{\gamma}_{\mathrm{SO}_{4}}^{--}$ & 1.00 & 1.00 & 0.26 & 0.09 & 0.02 & 0.02 \\
\hline $\mathrm{pK}_{\mathrm{sp}}^{3} \mathrm{Ca}(\mathrm{OH})_{2}$ & & & 5.44 & 5.43 & 5.44 & 5.19 \\
\hline $\mathrm{pK}_{\mathrm{sp}}{ }^{4} \mathrm{Ca}(\mathrm{OH})_{2}$ & 5.33 & 5.26 & 5.21 & 5.21 & 5.21 & 5.19 \\
\hline $\begin{array}{l}\mathrm{pK}_{\mathrm{sp}}^{3} \\
\mathrm{CaSO}{ }_{4} \cdot 2 \mathrm{H}_{2} \mathrm{O}\end{array}$ & & & 4.38 & 4.39 & 4.37 & 4.47 \\
\hline $\begin{array}{l}\mathrm{pK}_{\mathrm{sp}}{ }^{4} \\
\mathrm{CaSO}_{4} \cdot 2 \mathrm{H}_{2} \mathrm{O}\end{array}$ & 4.15 & 5.04 & 4.31 & 4.31 & 4.31 & 4.36 \\
\hline
\end{tabular}

1 Solubility constant data from Lide (1993).

2 Solubility constant data from Dean (1992).

${ }^{3} \mathrm{~K}_{\mathrm{sp}}$ calculated from concentration and activity coefficient results.

${ }^{4} K_{s p}$ calculated from standard free energy of formation in references or database. 
Table IV. Amounts of precipitates and solution properties from Problem \#4.

\begin{tabular}{|c|c|c|c|c|c|}
\hline & $\begin{array}{c}\text { Ideal Solution } \\
\# 1^{1} \\
\end{array}$ & COM, & COM, B-dot & PIT & HMW \\
\hline \multicolumn{6}{|c|}{ Precipitate Name and Amount ( $(\Omega /)$} \\
\hline $\mathrm{Ca}(\mathrm{OH})_{2}$ & 0.09 & 1.11 & 1.00 & 1.45 & 29.3 \\
\hline $\mathrm{NaCl}$ & 162.2 & 154.2 & 147.4 & 167.8 & 168.2 \\
\hline $\mathrm{Na}_{2} \mathrm{SO}_{4}$ & 4.08 & 7.54 & 5.25 & 5.95 & 5.95 \\
\hline $\mathrm{Na}_{2} \mathrm{Ca}\left(\mathrm{SO}_{4}\right)_{2}$ & 0.17 & 3.81 & 8.05 & 5.00 & 4.40 \\
\hline \multicolumn{6}{|c|}{ Solution Properties (unitless unless noted) } \\
\hline $\mathrm{pH}$ & 14.1 & 13.2 & 13.2 & 13.6 & 13.7 \\
\hline$\left[\mathrm{Ca}^{++}\right], \mathrm{M}$ & 0.0 & 0.0002 & 0.003 & 0.001 & 0.001 \\
\hline$\left[\mathrm{Na}^{+}\right], \mathrm{M}$ & 7.66 & 4.75 & 7.119 & 6.99 & 6.97 \\
\hline$[\mathrm{Cl}], \mathrm{M}$ & 5.03 & 4.33 & 6.49 & 5.57 & 5.44 \\
\hline$\left[\mathrm{OH}^{-}\right], \mathrm{M}$ & 1.361 & 0.06 & 0.09 & 0.10 & 0.14 \\
\hline$\left[\mathrm{SO}_{4}^{-}\right], \mathrm{M}$ & 0.648 & .0 .3 & 0.08 & 0.67 & 0.70 \\
\hline${ }^{\gamma} \mathrm{Ca}^{++}$ & 1.00 & 21.82 & 0.65 & 3.55 & 2.43 \\
\hline$\gamma_{\mathrm{Na}^{+}}$ & 1.00 & 3.41 & 1.55 & 1.86 & 1.84 \\
\hline$\gamma_{\mathrm{Cl}^{-}}$ & 1.00 & 0.55 & 0.53 & 0.53 & 0.53 \\
\hline$\gamma_{\mathrm{OH}^{-}}$ & 1.00 & 0.55 & 0.53 & 0.41 & 0.30 \\
\hline $\mathrm{\gamma}_{\mathrm{SO}_{4}}^{---}$ & 1.00 & 0.56 & 0.05 & 0.005 & 0.005 \\
\hline $\mathrm{pK}_{\mathrm{sp}}^{3} \mathrm{Ca}(\mathrm{OH})_{2}$ & & 5.44 & 5.44 & 5.44 & 5.19 \\
\hline $\mathrm{pK}_{\mathrm{sp}}^{4} \mathrm{Ca}(\mathrm{OH})_{2}$ & 5.21 & 5.21 & 5.21 & 5.21 & 5.19 \\
\hline $\mathrm{pK}_{\mathrm{sp}}{ }^{3} \mathrm{NaCl}$ & & -1.59 & -1.59 & -1.59 & -1.57 \\
\hline $\mathrm{pK}_{\mathrm{sp}}^{4} \mathrm{NaCl}$ & -1.59 & -1.59 & -1.59 & -1.59 & -1.57 \\
\hline $\mathrm{pK}_{\mathrm{sp}}{ }^{3} \mathrm{Na}_{2} \mathrm{SO}_{4}$ & & 0.31 & 0.31 & $\overline{0.31}$ & 0.29 \\
\hline $\mathrm{pK}_{\mathrm{sp}}^{4} \mathrm{Na}_{2} \mathrm{SO}_{4}$ & 0.31 & 0.31 & 0.31 & 0.31 & 0.29 \\
\hline $\mathrm{pK}_{\mathrm{sp}}{ }^{3} \mathrm{Na}_{2} \mathrm{Ca}\left(\mathrm{SO}_{4}\right)_{2}$ & & 5.47 & 5.47 & 5.47 & 5.25 \\
\hline $\mathrm{pK}_{\mathrm{sp}}{ }^{4} \mathrm{Na}_{2} \mathrm{Ca}\left(\mathrm{SO}_{4}\right)_{2}$ & 5.47 & 5.47 & 5.47 & 5.47 & 5.24 \\
\hline
\end{tabular}

1 Solubility constant data from Lide (1993).

2 Solubility constant data from Dean (1992).

${ }^{3} \mathrm{~K}_{\mathrm{sp}}$ calculated from concentration and activity coefficient results.

${ }^{4} \mathrm{~K}_{\mathrm{sp}}$ calculated from standard free energy of formation in references or database. 